\title{
Estrategias territoriales y usos políticos de la identidad en el interfluvio Teuco-Bermejito, Chaco*
}

\section{Territorial strategies and political uses of the identity in the Teuco-Bermejito drainage divide, Chaco}

\author{
Cesar Abel Gomez ${ }^{* *}$
}

\section{Resumen}

El artículo presenta una caracterización de las estrategias territoriales asumidas por las organizaciones de indígenas y criollos en el marco de disputas por el acceso a la tierra en el Interfluvio Teuco-Bermejito, en la provincia del Chaco. A partir del proceso de territorialización iniciado por la Asociación Comunitaria Meguesoxochi para defender sus posesiones ante el avance de empresas forestales en el Interfluvio, la entrega del título comunitario a favor del pueblo qom como reparación histórica derivó en un escenario de disputas entre pobladores indígenas y criollos. Señalamos que la modalidad de apropiación del espacio encarada por la Asociación Meguesoxochi se basa, centralmente, en una estrategia que promueve una territorialidad étnica excluyente.

\footnotetext{
* Artículo recibido el 28 de Septiembre de 2015. Aceptado el 9 de Diciembre de 2015.

** Universidad Nacional del Nordeste. Argentina.

Correo electrónico: cesarabelgomez@gmail.com
} 


\section{Abstract}

This article presents a characterization of territorial strategies undertaken by indigenous and creole people organizations under disputes over access to land at Teuco-Bermejito Interfluve, in the province of Chaco. From territorialization process initiated by the organization called Asociación Comunitaria Meguesoxochi to defend their possessions against the advance of forest companies in the Interfluve, delivery of communal land title for qom people in respect of historical reparation resulted in a flashpoint between indigenous and creole people. We note that the mode of appropriation of space facing by Asociación Meguesoxochi is based centrally in a strategy that promotes an exclusionary ethnic territoriality.

\section{Palabras clave}

Territorio - Etnicidad - Interculturalidad.

\section{Keywords}

Territory - Ethnicity - Interculturality.

\section{La reserva como dispositivo de territorialización}

Hacia fines del siglo XIX los pueblos indígenas aún ejercían control sobre vastas porciones del actual territorio argentino. Esas áreas evidenciaban la existencia de fronteras interiores que separaban el espacio 'civilizado', ocupado por la sociedad mayoritaria, respecto del 'desierto bárbaro' en el que los indígenas mantenían una relativa autonomía. Cuando, a partir de la década de 1870, esas fronteras se convirtieron en obstáculos para la consolidación de la sociedad nacional en expansión, el avance y ocupación militar sobre los territorios indígenas fueron objetivos prioritarios de los sectores dirigentes.

En el norte, avanzar sobre la frontera en la zona del Chaco representaba la posibilidad de desarrollar proyectos colonizadores y someter a los indígenas para incorporarlos al esquema productivo de las industrias extractivas. La Conquista del Desierto que impulsó el Gral. Roca en la Patagonia tuvo su correlato en el Chaco desde 1884, con la ofensiva del Ministro de Guerra Benjamín Victorica. Los indígenas fueron progresivamente desplazados de las mejores tierras por los embates de las incursiones militares, por lo que encontraron cada vez mayores dificultades para mantener sus formas de reproducción tradicionales. Al no poder acceder a los montes y los ríos, para garantizar sus condiciones de subsistencia tuvieron que incorporarse tempranamente como mano de obra en las actividades productivas que constituían la avanzada capitalista en el territorio. 
En primera instancia, fueron solicitados por la industria forestal como hacheros y en las tareas de más baja calificación; poco después se sumaron los requerimientos de los ingenios azucareros, que fomentaron importantes corrientes migratorias estacionales. Con la expansión del cultivo de algodón a partir de la década de 1920, miles de chacras de colonos europeos sumaron la demanda de brazos para las tareas de carpida y cosecha. En ese sentido, la cesión de tierras a los grupos indígenas sometidos tuvo como objetivo fomentar prácticas que sustituyeran sus estrategias de reproducción tradicionales, como la caza y la recolección. Fue habilitada desde el Estado nacional con el propósito de ceder una suerte de 'retaguardia' territorial, como política de integración y como concesión posterior al despojo de sus territorios, a la vez que era una forma de territorializar a los grupos nómades y garantizar su control y disponibilidad.

En muchos casos, las tierras entregadas eran escasamente productivas y no revestían interés para el avance de la colonización privada. Por otra parte, la cesión generalmente consistía en la entrega de tierra fiscal para el usufructo comunitario por parte de los indígenas, aunque el Estado conservaba la potestad de destinarlas para otro uso si fuera conveniente (Martínez Sarasola, 1992; Mases, 2000). Como dispositivo oficial de poblamiento, si bien la reserva no estaba destinada exclusivamente a los indígenas porque el ejecutivo podía 'reservar' tierras y luego proyectar el trazado de colonias agrícolas o pastoriles para otros destinatarios-, para este grupo social implicó una forma de territorialización particular que se diferenció de la reducción o la colonia por la ausencia de un plan de gestión y supervisión por parte de los funcionarios. Frente a la presión disciplinadora que suponía la reducción, la reserva posibilitaba un margen de relativa autonomía. No obstante, cabe señalar que, durante esta etapa, la reducción fue el dispositivo que expresó y sintetizó al paradigma indigenista, mientras que las reservas fueron un recurso utilizado en forma relativamente aislada.

La reserva indígena de la Colonia Teuco fue quizá la experiencia más significativa desarrollada con este dispositivo específico en el territorio chaqueño, por la extensión de superficie afectada y porque fue una de las pocas que el poder Ejecutivo refrendó formalmente. Nos interesa en forma particular este caso porque constituye el antecedente jurídico sobre el cual, más de seis décadas después, se fundó el reclamo territorial que sostuvo el pueblo qom a través de la Asociación Meguesoxochi.

\section{El antecedente de Colonia Teuco}

En forma simultánea al proceso de ocupación del espacio impulsada con la instalación del esquema agroforestal, desde fines del siglo XIX en el oeste del territorio chaqueño se desarrollaron formas de colonización irregular promovidas principalmente por productores ganaderos que provenían de Santiago del Estero y de Salta. Las familias criollas se asentaron en áreas que correspondían a los frentes de avance de las columnas militares, principalmente en las zonas de mejores pastizales en las márgenes 
de los ríos, donde las tierras eran especialmente aptas para la ganadería extensiva (Beck, 1994; Jacob, 1994). Esa forma de ocupación determinó que aun después de su incorporación a la órbita estatal, la región noroeste se mantuviera como un 'territorio fronterizo', pues se convirtió en punto de encuentro de grupos criollos e indígenas que se disputaron la apropiación del espacio. La zona del Interfluvio Teuco-Bermejito, en el actual departamento de General Güemes (ver FIGURA 1), ${ }^{1}$ fue rápidamente ocupada por asentamientos ganaderos, aunque allí también se concentraban numerosos grupos indígenas que fueron progresivamente desplazados de otras áreas por el ejército. Pronto se generaron situaciones de conflicto en virtud de que las formas de reproducción social de ambos grupos se tradujeron en territorialidades superpuestas en competencia por los recursos. Mientras que los indígenas utilizan el monte para mariscar, los criollos mantienen una forma de explotación ganadera extensiva, ocupando áreas que no están delimitadas más que por los propios animales en su deambular a campo abierto.

En el marco de la ley de tierras 4167, que desde comienzos del siglo XX reemplazó a la frustrada ley Avellaneda, el área fue parcialmente afectada por sucesivos instrumentos legales con los que se intentó territorializar a la población a través de la creación de colonias o reservas. Con el propósito de trazar una colonia agrícola, en 1911 se reservaron, por decreto, 50 mil hectáreas, que poco después fueron mensuradas, alentando de este modo la llegada de familias criollas al Interfluvio. Sin embargo, esa proyección fue dejada sin efecto en 1921 con la creación de la Colonia Pastoril Teuco, con unas 250000 hectáreas que abarcaban desde la confluencia del Teuco y el Bermejito hasta lindar hacia el oeste con la propiedad de la sociedad anónima "Explotación Campos y Montes Río Bermejo" -hoy Estancia La Fidelidad. La conflictividad en la zona pronto comenzó a intensificarse porque los criollos fueron habilitados a instalarse y los indígenas a su vez reclamaron el derecho a permanecer en las tierras en virtud de supuestos acuerdos con el gobierno nacional. ${ }^{2}$

\footnotetext{
${ }^{1}$ El Interfluvio abarca el área comprendida hacia el oeste desde la confluencia de los cauces de los ríos Teuco y Bermejito. "Geomorfológicamente, forma parte de la dilatada cuenca sedimentaria de compleja morfogénesis que constituye la llanura chaqueña, con depósitos aluviales del Bermejo y áreas inundables. Los valles e interfluvios netamente definidos han surgido como consecuencia del desplazamiento del río Bermejo hacia el actual cauce del río Teuco" (PDITB-Programa Sustentabilidad Ambiental, 2001: 6). Comprendida dentro de esta micro-región, el área en cuestión abarca unas 214000 hectáreas delimitadas en torno del paraje denominado Colonia Teuco, desde la confluencia hasta aproximadamente unos 85 kilómetros hacia el oeste, entre el paralelo de $25^{\circ}$ y meridiano de $60^{\circ}$. Se trata de la superficie afectada en el marco del proceso iniciado a partir de la restitución de tierras a las comunidades indígenas, por lo que 150000 hectáreas corresponden a propiedades de las comunidades y 64000 hectáreas están destinadas a la relocalización de la población criolla.

${ }^{2}$ Aunque no hay datos precisos, algunos relatos coinciden en señalar que durante 1917 varios caciques hicieron un viaje a Buenos Aires para entrevistarse con Yrigoyen y solicitarle la entrega de tierras. Probablemente se trate del mismo episodio que involucra a Taigoyic como antecedente de la creación de una reserva en la zona de Pampa del Indio.
} 
Luego de algunos incidentes entre los pobladores, que derivaron en enfrentamientos entre la Gendarmería y grupos de indígenas (Jacob, 1994: 196), en febrero de 1924 el presidente Alvear firmó un decreto a través del cual quedaron reservadas $150 \mathrm{mil}$ hectáreas dentro de la Colonia Teuco para ser ocupadas exclusivamente por "los indios tobas del norte". A la vez, se encomendó a la Dirección General de Tierras para facilitar la concentración de los indígenas en el área señalada. Entre los considerandos del decreto se señaló que la medida apuntaba a "regularizar la situación de esos indígenas que actualmente por falta de ubicación precisa se ven obligados a deambular sin destino" (B.O.,1924: 467).

Al año siguiente, otro decreto ordenó trazar el límite noroeste de la reserva, pero aquella sería la última medida promovida oficialmente para garantizar que los indígenas tuvieran su posesión efectiva y exclusiva. En 1931, el gobernador Mac Lean solicitó sin éxito a la Oficina de Tierras el desalojo de los intrusos, ${ }^{3}$ por lo que, a lo largo de siete décadas, indígenas y criollos convivieron en el Interfluvio sin que se produjeran avances en la regularización de la situación dominial de las tierras. Para la década de 1940, un informe generado por una comisión especial de la Dirección de Tierras que recorrió la colonia señaló que

(...) en la mitad de esa extensión se encuentran las fracciones denominadas reserva indígena y zona sin mensura (...) En la primera hay 744 aborígenes y cien familias de ganaderos, totalizando éstas 430 personas. Viven allí, en consecuencia, 1174 pobladores. Los indígenas se dedican en pequeña escala a cultivar la tierra y se ocupan generalmente como peones o braceros, dentro y fuera del territorio; las familias de ganaderos han realizado mejoras de importancia sobre 108.025 hectáreas que explotan. Los indígenas (...) siembran algodón, maíz y batata en extensiones que no pasan de las cinco hectáreas. En la zona no hay autoridad y esto permite a los más indolentes apropiarse de animales ajenos para alimentarse. La última inspección a este lugar se realizó hace mucho y no hay referencia de que las autoridades hubiesen adoptado medida alguna a favor de esos aborígenes (Asociación de Fomento de Chaco y Formosa, 1944: 30).

Cuando se promovió la provincialización del territorio en 1951, con la ley 14 037, se estableció que toda la legislación correspondiente a la etapa previa quedaría en vigor, lo que garantizó la continuidad del derecho de los indígenas sobre las tierras del Interfluvio. No obstante, desde ese momento el decreto de Alvear pasó al olvido, ya que resoluciones posteriores omitieron cualquier referencia a la reserva; incluso a fines de los años setenta se entregaron algunos títulos individuales a favor de familias indígenas, lo que significó desconocer aquel antecedente.

Cuando, en la década de 1980, el gobierno provincial comenzó a promover nuevas adjudicaciones en forma masiva dentro del Interfluvio, el avance de nuevos propietarios

\footnotetext{
${ }^{3}$ Archivo Histórico provincial del Chaco. Copiador de la Secretaría de Gobernación, Tomo 76, p. 927-928. Citado en Jacob (1994)
} 
sobre el territorio configuró un nuevo escenario de conflicto y se dieron las condiciones para traer a la memoria y recuperar aquel decreto de 1924.

\section{La Asociación Comunitaria Meguesoxochi}

Hacia mediados de la década de 1980 el Instituto de Colonización de la Provincia de Chaco comenzó a ofrecer adjudicaciones en venta en un área de 50 mil hectáreas dentro de la Colonia Teuco, basándose en una nueva ley que reglaba el manejo de las tierras fiscales. Frente al avance del proceso privatizador, los indígenas del Interfluvio se movilizaron para denunciar las acciones del organismo y fundamentaron su rechazo en la existencia del antecedente que les daba derechos sobre las tierras: el decreto de creación de la reserva indígena del 19 de febrero de 1924. En el mes de agosto de 1989 se realizó una asamblea multitudinaria en la comunidad de Lapelolé; más de un millar de personas se reunieron y resolvieron adoptar un plan de acción para recuperar las 150000 hectáreas de la reserva. En primera instancia, se decidió crear una comisión cuyos objetivos serían lograr el reconocimiento de los derechos territoriales adquiridos y la recuperación efectiva de las tierras. ${ }^{4}$ Al poco tiempo, la comisión quedó formalizada bajo la denominación de Asociación Comunitaria Meguesoxochi (MEGUE) ${ }^{5}$ y asumió la figura jurídica de asociación civil, para ajustarse a las condiciones establecidas en la normativa provincial, regida por un estatuto y con una comisión directiva renovable cada dos años a través del voto de los socios en asamblea general ordinaria. Así, la organización tomó un perfil en el que se enlazaron una dimensión reivindicativa, expresada en sus objetivos fundacionales, con una dimensión representativa emanada desde las comunidades como base territorial. Aunque asumió la representación de las comunidades indígenas comprendidas en el área de la reserva, ${ }^{6}$ entre sus socios también había indígenas de las comunidades vecinas, como Fortín Lavalle y El Colchón, ya que la única condición formal para pertenecer a asociación fue la pertenencia al pueblo qom.

En 1991, luego de varias asambleas, reuniones y gestiones ante distintos funcionarios, con el decreto 116 se reconoció el derecho de las comunidades sobre las 150000 hectáreas otorgadas por Decreto Nacional del 19 de febrero de 1924 (art. $1^{\circ}$ ). A partir de allí, se abrió una nueva etapa, pues quedaba pendiente lograr la posesión jurídica a

\footnotetext{
4 La Asociación recibió el nombre de Meguesoxochi en homenaje a uno de los caciques qom que encabezó la resistencia frente a la avanzada del ejército a fines del siglo XX. Se le atribuían poderes especiales; según cuentan los ancianos, Meguesoxochi se entregó al ejército y luego fue trasladado en barco con un destino incierto. Algunas versiones dicen que fue asesinado en ese trayecto, mientras que existen testimonios que señalan que permaneció con vida muchos años más y fue visto en distintos lugares.

5 "Megue" es el diminutivo con el que se nombra a la Asociación en la zona en el marco del discurso corriente. En adelante, para más practicidad y para compensar la redundancia usaremos esa denominación.

${ }^{6}$ Lapelolé (La Confluencia), La Sirena, Paso Sosa, Olla Quebrada, Víbora Blanca, Río Muerto, El Simbolar, Pozo del Bayo, Campo Azul, El Algarrobal, Las Palomas, Las Tunillas, Palma Sola, Tres Pozos y La Bolsa.
} 
través de la titularización comunitaria. Quedó establecido que, en adelante, sería necesario determinar el real estado de ocupación de las tierras del Interfluvio y se encomendó la realización de un relevamiento poblacional (art. $2^{\circ}$ ). Debían adoptarse las medidas necesarias para compensar la superficie reservada en 1924 en caso de que existieran ocupantes habilitados por instrumentos legales preexistentes a esa fecha (art. $\left.3^{\circ}\right)$, mientras que para los ocupantes no indígenas que debieran ser desalojados se contempló como compensación la reubicación en zonas aledañas (art. $4^{\circ}$ ). De presentarse situaciones problemáticas se buscaría el acuerdo entre las partes, pero tendría prioridad el interés de los indígenas (art. $5^{\circ}$ ). Por último, la propiedad de las tierras quedaría definida en el otorgamiento de un título a favor de las asociaciones comunitarias correspondientes (art. $\left.6^{\circ}\right) .^{7}$

Para eso era necesario, en primera instancia, realizar la mensura y delimitación del área correspondiente, un proceso que, con avances y retrocesos, se extendió hasta mediados de 1999. Durante esa etapa la MEGUE se debatió entre la imposibilidad de ejercer una participación efectiva para garantizar el cumplimiento efectivo de lo ordenado por el decreto y una constante actitud propositiva para dar cuenta de su capacidad de proyección y gestión del territorio reivindicado.

En junio de 1999, la organización indígena recibió del gobierno provincial el título de propiedad comunitaria de 139138 hectáreas bajo el concepto de reparación histórica. Esa superficie se sumó a otras 10000 hectáreas entregadas en forma de propiedad privada individual en 1981-82. De ese modo, el territorio en poder de la población qom del Interfluvio sumó una superficie de 149138 hectáreas.

A partir de la titularización comunitaria, los pobladores criollos del Interfluvio quedaron como 'intrusos' asentados en propiedad indígena. Esto modificó la relación entre ambos grupos sociales al alterar vínculos de subordinación sedimentados a lo largo de casi un siglo de convivencia. Tras atravesar diversas instancias de negociación, la nueva situación llevó a la necesidad de encarar un proceso de reasentamiento de la población y regularización dominial. Con el propósito de evitar conflictos interétnicos y pleitos judiciales, el gobierno provincial impulsó entonces el Proyecto de Desarrollo Integrado Teuco-Bermejito (PDITB), un programa destinado a la reubicación de 290 familias criollas, que contemplaba un plazo de cinco años para cumplir las tareas previstas, con una restricción de uso a favor de los criollos que serían relocalizados. En esa instancia, que requería de la participación de los pobladores que se verían afectados, un grupo de criollos constituyó la Asociación F.OR.T.IN, cuyo nombre es una sigla que resume "Familias Organizadas por las Tierras del Interfluvio", pero que remite también a un pasado de enfrentamientos y disputas territoriales con los indígenas. Se

\footnotetext{
${ }^{7}$ El Decreto 116 fue modificado ese mismo año en sus artículos $2^{\circ}$ y $6^{\circ}$ por el Decreto 767 . Se explicitó que sería necesario dar participación a los pobladores no indígenas en el relevamiento de población, a la vez que se indicó que serían las Asociaciones comunitarias -y no el IDACH, como se indicaba en el decreto 116- las receptoras del título de propiedad.
} 
constituyó desde entonces un campo de disputas y negociaciones en torno a las características que debía asumir el proceso de relocalización, ya que los criollos reclamaron también el reconocimiento de derechos sobre las tierras que ocupaban, en algunos casos desde principios de siglo (Balazote, 2002; Balazote y Radovich, 2003).

Luego de un primer año de diseño de los distintos programas de intervención, siguió una 'etapa de transición' en la que se desarrollaron acciones preparatorias para la implementación de las relocalizaciones, cuyo inicio quedó programado para finales del tercer año de proyecto. Recién hacia 2002 comenzarían las mensuras correspondientes a la primera etapa, que afectaría a unas 150 familias. $^{8}$

Al día de hoy, 16 años después de la entrega del título, el proceso tal como fuera programado inicialmente se cumplió en forma parcial y desordenada. Los sucesivos gobiernos no atendieron los compromisos asumidos con las familias que fueron relocalizadas, por lo que los conflictos y tensiones se mantienen vigentes y los pobladores criollos se resisten a abandonar las tierras que ocupan.

En el contexto de la agudización de los procesos de pauperización social que afecta por igual a indígenas y criollos, la disputa territorial ha sido caracterizada en forma recurrente como "una guerra entre pobres". Esto se ha expresado en un complejo juego de oposiciones en el que sus estrategias han estado centradas en procesos de afirmación identitaria que tienden a reforzar las diferencias culturales en referencia a una adscripción étnica. Así como las comunidades qom centraron su demanda en el marco jurídico que posibilitó la restitución de sus tierras a modo de reparación histórica, los criollos desplegaron también una serie de acciones que se orientan a legitimar sus reclamos en el plano simbólico a través de la recreación de un repertorio cultural asociado con las 'tradiciones criollas' (Barrios, 2005).

\section{Hacia una caracterización de las estrategias territoriales}

Al hablar de las disputas por el acceso a la tierra hacemos referencia a la tensión existente entre distintas formas de apropiación del espacio. En ese sentido, la incorporación de nociones de territorio y territorialidad permite dar cuenta de problemáticas en las que se articulan relaciones de dominación, disputas en torno a la apropiación de recursos y procesos de construcción identitaria por parte de sujetos colectivos.

Para Claude Raffestin (1993) las representaciones son mediaciones que permiten sustantivar el territorio a partir del espacio. La dimensión espacial constituye su

\footnotetext{
${ }^{8}$ El plazo de cinco años fijado al inicio del proyecto se venció en abril de 2004 y no se habían concretado traslados de población. Entonces, el gobierno propuso una reprogramación de las actividades y firmó sucesivos convenios con la MEGUE para formalizar la prórroga. En el nuevo esquema de trabajo se había proyectado avanzar con 30 traslados durante 2004, 23 durante 2005 y 97 en el 2006, para totalizar 150 familias relocalizadas en la etapa A del proyecto, que abarcaría el área comprendidas por las parcelas 404 y 16. Se preveía además completar la etapa B durante el año 2007 con la concreción de otros 150 traslados. Al día de la fecha solo se cumplieron parcialmente los objetivos correspondientes a la etapa A.
} 
condición y fundamento, pero como una abstracción que se concretiza a través de la acción de un "actor sintagmático" que lleva adelante un programa. Entonces, el espacio, una vez representado, ya no es espacio sino territorio, es el resultado de un proceso social de apropiación.

Este giro cultural derivó hacia una noción multidimensional del territorio. Milton Santos (2000) definió al espacio -en una acepción similar- como un híbrido de sistemas de objetos y sistemas de acciones para señalar de ese modo la imposibilidad de mantener la división entre lo material y lo simbólico; también Haesbaert (2004) definió territorio como el resultado de un proceso de territorialización que implica un dominio (aspecto económico-político) y una apropiación (aspecto simbólico-cultural) de los espacios por los grupos humanos. ${ }^{9}$

Aunque la lucha por la restitución y/o reconocimiento de las tierras ancestrales indígenas es de larga data, la perspectiva que la ubica como una idea que trasciende lo exclusivamente material es relativamente reciente, coincidiendo con la resignificación de la lucha indígena de las últimas décadas (Bello, 2004). La idea de territorialidad remite en estos casos a un elemento constitutivo de la identidad colectiva como un rasgo singular.

A través de la noción de estrategias territoriales propusimos un análisis de las distintas formas de apropiación del espacio en las que se ponen en juego -se construyen, recrean- identidades específicas. ${ }^{10}$ Al hablar de estrategia territorial nos referimos al curso de acción definido por un colectivo en el marco de disputas por la apropiación del espacio con otro/s agente/s, orientado a facilitar el acceso a la tierra, mantenerlo en los casos en que este se vea amenazado, o efectivizarlo a partir de la reivindicación de un derecho específico. A través de un conjunto de prácticas referenciadas en un colectivo, se genera un proceso de construcción identitaria que toma como referencia privilegiada una forma específica de apropiación del espacio, como un aspecto constitutivo de la identidad, de la territorialidad de un grupo social.

Para dar cuenta de la dimensión territorial de las estrategias, debemos circunscribir la mirada en torno de aquellas prácticas que suponen una forma directa de apropiación

\footnotetext{
${ }^{9}$ Partiendo de la idea de que no hay apropiación material que no sea a la vez simbólica, el territorio se constituye como un instrumento heurístico que permite integrar ambas dimensiones sin compartimentar la realidad en la reproducción de alguna de las variantes del dualismo epistemológico: acción/estructura, subjetivismo/objetivismo, cultura/naturaleza, etc. La noción es útil porque nos permite evitar dos formas comunes de reduccionismo: por una parte, del objetivismo de las estructuras materiales que limitan la concepción del espacio geográfico a un sustrato físico-natural, y, por otra parte, del constructivismo radical que lo reduce al efecto de formas cognitivas. Se trata de una apuesta por integrar en el análisis los factores estructurales que configuran los escenarios y los diversos sentidos que se ponen en las formas de apropiación del espacio, o de concebir el vínculo con la tierra.

${ }^{10}$ Según Robert Sack, la territorialidad es "una tentativa o estrategia, de un individuo o un grupo para alcanzar, influenciar o controlar recursos y personas a través de la delimitación y del control de áreas específicas" (Sack, 1986: 19).
} 
del espacio, ya sea que se expresen en el plano simbólico o material. Las prácticas que se inscriben en la estrategia territorial no necesariamente tienen, si las consideramos en forma aislada, un correlato territorial inmediato, sino que contribuyen a generar una forma de territorialidad cuando se inscriben en el marco de un sistema.

En nuestra caracterización, las prácticas de los agentes estudiados fueron agrupadas bajo una serie de categorías que remiten a las dimensiones constitutivas de la estrategia territorial como un sistema: estrategias de reivindicación, estrategias de delimitación, y estrategias de posesión y gestión, condicionadas a su vez por una red de alianzas con otros agentes del espacio social. Cada una de esas dimensiones remite a un conjunto de prácticas promovidas por las organizaciones en tanto agentes que recrean sus identidades colectivas a través de formas específicas de uso y apropiación del espacio. Fue necesario, en primer lugar, organizar la información disponible bajo la forma de unidades analizables, por lo que agrupamos las prácticas de los agentes en diferentes categorías que asumimos como dimensiones constitutivas de la estrategia territorial. ${ }^{11}$

En la trayectoria de la Asociación Meguesoxochi identificamos tres etapas o momentos diferenciados que se corresponden con avances sucesivos de su proceso de territorialización. La secuencia se ordena cronológicamente del siguiente modo:

Fase reivindicativa, desde los inicios de la organización, en 1989, con reclamos y gestiones que se orientaron a conseguir el reconocimiento de derechos adquiridos sobre el territorio. Las acciones se concentraron en el plano reivindicativo, con intervenciones destinadas, por un lado, a instalar el problema en el espacio público y, por otro, a darle un marco jurídico.

Fase de demarcación, desde la sanción del decreto 116 hasta junio de 1999, cuando el gobierno provincial entregó el título comunitario. Esta etapa estuvo jalonada de diferentes obstáculos que demoraron el proceso de delimitación territorial; frente a la arbitrariedad de los procedimientos iniciados por los

\footnotetext{
${ }^{11}$ Los datos utilizados fueron obtenidos, principalmente, de fuentes secundarias que abarcan una gran cantidad de documentos: materiales textuales de difusión generados por las organizaciones indígenas y por las ONG involucradas en los procesos de territorialización; estadísticas oficiales; documentación alojada en archivos de instituciones públicas; informes y documentos generados en el marco de los programas oficiales de intervención en las áreas de estudio (principalmente los programas aplicados en el Interfluvio Teuco-Bermejito), etc. Asumimos que estas fuentes conllevan limitaciones propias de su especificidad, como la selectividad implicada en su producción, o su interpretabilidad múltiple y cambiante, por lo que las incorporamos al análisis como productos sociales. Otorgarles un espacio de consideración diferenciado supone asignarles la pretensión de erigirse como representaciones válidas de una realidad objetiva, mientras que su análisis requiere, precisamente, la tarea interpretativa de comprender los contextos de producción de dichos materiales (Hammersley y Atkinson, 1994). En muchos casos la parcialidad que se les adjudica constituye una fuente de información en sí misma más que una amenaza para su validez. De esta forma asumimos la intencionalidad implicada en su producción, "tan importante como la objetividad o la adecuación a la realidad del relato determinado, es lo que éste nos dice sobre la perspectiva y los presupuestos del autor" (Hammersley y Atkinson, 1994:146).
} 
organismos oficiales en las tareas de mensura, la organización presentó propuestas de delimitación alternativas.

Fase de toma de posesión efectiva y gestión, a partir de la entrega del título, los criollos asentados en territorio indígena pasaron a ser intrusos en propiedad privada, por lo que hubo que encarar un proceso de relocalización para que los dueños pudieran ocupar y hacer uso del territorio. En esta etapa -que se extiende hasta nuestros días-, la Asociación toma decisiones sobre el territorio, aunque no detenta la posesión efectiva.

En síntesis, primero fue necesario el reconocimiento de derechos, luego, delimitar el territorio $y$, por último, su toma de posesión y usufructo efectivo -aún sin cumplimentar. Esto no significa que las prácticas de la organización en cada fase se perfilen de forma exclusiva sobre un único aspecto, ya que la estrategia territorial involucra simultáneamente formas de reivindicar, delimitar y gestionar el territorio. Aunque se presenten de modo sincrónico y articulado, en cada fase hay una dimensión de la territorialidad que prevalece sobre el resto y opera como el eje que estructura el sistema. En la estrategia de la Asociación Meguesoxochi los tres niveles se sucedieron de modo progresivo a medida que el proceso de territorialización avanzaba en concreción; diacrónicamente, la estrategia trazó un recorrido que comenzó con la disputa en el plano simbólico y luego dio lugar a sucesivos intentos por avanzar con la apropiación material.

\section{De los agujeros del queso al territorio exclusivo}

Inicialmente, la organización indígena se orientó según una oposición entre pobladores y no-pobladores; indígenas y criollos compartían una situación de vulnerabilidad frente a una amenaza externa encarnada en la llegada de empresarios forestales y nuevos propietarios. Una vez cumplido el logro jurídico, el proceso de territorialización ingresó a otra instancia cuando se trató de materializar la reivindicación formal. Cuando fue necesario delimitar el área a través del proceso de mensura, en la disputa por el acceso a la tierra, la oposición pasó a enfrentar a propietarios e intrusos.

Durante la fase de demarcación y hasta la obtención del título comunitario en 1999, la Asociación se debatió entre la imposibilidad de ejercer una participación efectiva en la mensura y una constante actitud propositiva para dar cuenta de su capacidad de proyección y gestión del territorio reivindicado. Los avatares del proceso de mensura evidenciaron que, aunque la Asociación contó desde 1991 con instrumentos legales para avalar su derecho sobre el territorio, existía una fuerte incongruencia entre esa territorialidad jurídica y el territorio real, efectivamente reconocido y recreado por las prácticas de los distintos agentes involucrados. Esa no correspondencia se dirimía en la capacidad efectiva de la Asociación de desplegar una estrategia eficaz para apropiarse del espacio reivindicado. 
Hacia 1991, el área bajo posesión de los indígenas en el Interfluvio abarcaba unas 10000 hectáreas regularizadas con títulos individuales, junto a la ocupación efectiva de predios de no más de 20 hectáreas por parte de las distintas comunidades representadas por la Asociación Meguesoxochi. El resto de la Colonia Teuco estaba irregularmente poblada por familias criollas dedicadas a la ganadería extensiva en predios sin límites definidos. A partir de una situación defensiva, de resistencia, con las comunidades confinadas en espacios reducidos o en parcelas individuales como resultado de un proceso histórico de arrinconamiento en una territorialidad subordinada, la recuperación del territorio demandaba construir una nueva territorialidad.

Aunque el decreto 116 prefiguraba un conflicto potencial en virtud de que hacía mención al eventual desalojo de ocupantes no indígenas, al principio la relación con los criollos no se concibió en términos antagónicos. El reclamo indígena se había activado para frenar el avance de las adjudicaciones y las nuevas ocupaciones, donde, si bien podía haber pobladores criollos involucrados, se trataba principalmente de empresarios arribados desde otras provincias. Aun cuando la falta de regularización dominial de las tierras ocupadas por indígenas y criollos se asumía como una situación problemática, ambos grupos podían confluir en un reclamo unificado. Al realizarse una segunda asamblea indígena en Olla Quebrada, en abril de 1990, antes de la sanción del decreto 116 , algunos pobladores criollos suscribieron un documento en el que manifestaron su apoyo al reclamo territorial de la MEGUE:

...pedimos participar de su asamblea en Olla Quebrada y escuchamos que ellos no se oponen a nuestra permanencia aquí con la condición de que seamos verdaderos pobladores, que ocupemos un espacio que corresponda a nuestras necesidades en un total respeto a la Naturaleza. Hoy nos damos cuenta que el peligro de desalojo no viene de ellos, sino de los hacendados y empresarios blancos que cada vez invaden más esta tierra... (Diario Norte, 1990: 8).

Estas intervenciones demuestran que, originalmente, el reclamo territorial no fue presentado como un antagonismo étnico dentro del Interfluvio. Indígenas y criollos promovieron declaraciones conjuntas en las que cuestionaban las dilaciones sistemáticas que obstaculizaban el proceso de mensura de la reserva. El reclamo de regularización dominial de las tierras se hacía extensivo hacia ambos grupos; como cuando expresaron estar "frustrados una vez tras otra, por las promesas que no se cumplen, los compromisos que se olvidan y la poca voluntad política de resolver definitivamente un problema de más de 60 años de existencia", a la vez que reafirmaban sus "buenas relaciones de vecindad y el propósito de trabajar juntos". (Diario Norte, 1993: 35).

El posicionamiento de la Asociación en esa instancia contrastó con posturas asumidas unos años después. Según documentos de la organización, hasta 1995 hubo una búsqueda de acuerdos para evitar que la delimitación territorial derivara en conflictos entre indígenas y criollos. En cambio, desde 1996 en adelante, el proceso de 
regularización dominial asumió un rumbo diferente cuando la solución promovida por el gobierno provincial -legitimada por la Asociación- consistió en la delimitación de áreas exclusivas para indígenas y criollos y en la proyección de un proceso de relocalización de población.

El primer posicionamiento podría sintetizarse en una propuesta presentada durante 1995, donde la Asociación sugería avanzar con un plan de mensura aproximada en base a la proyección de un área triangular de 150 mil hectáreas sobre el Interfluvio (ver Anexo, Figura 2). ${ }^{12} \mathrm{Si}$ bien esa propuesta remitía implícitamente a una posible relocalización, no mencionaba eventuales desalojos, sino que ofrecía a los pobladores criollos la posibilidad de elección: si optaban por obtener títulos de propiedad, deberían reubicarse en otro sitio en tierras entregadas por el Estado; si, en cambio, decidían permanecer en el lugar, se promovería la firma de acuerdos como vecinos para determinar las condiciones y normas de convivencia.

Aquel escenario se vio modificado desde 1996 con el recambio de autoridades provinciales, cuando los dirigentes de la Asociación y funcionarios de gobierno acordaron desafectar del proyecto de titulación comunitaria un área de casi 36000 hectáreas que comprendía parcelas previamente adjudicadas. ${ }^{13}$ El área contenía predios regularizados y quedaba reservada para el traslado de población criolla desde el territorio indígena, lo que implicaba necesariamente un reasentamiento forzoso de la población. Esta determinación introdujo un componente de discrecionalidad que habilitó el escenario para ulteriores conflictos, pues la definición en torno a quiénes deberían relocalizarse y quiénes podrían regularizar su situación se resolvía según criterios arbitrarios.

La alternativa contemplada previamente consistía en la conformación de enclaves no indígenas en aquellas parcelas de propietarios o adjudicatarios en venta -un modelo que suele ser referido como "los agujeros del queso"-. Sin embargo, a través de un proceso decisorio cuyos mecanismos no fueron formalmente explicitados, el gobierno provincial obtuvo el aval de la Asociación Meguesoxochi y de un sector de los criollos para avanzar según el esquema de las relocalizaciones. Si hasta 1996 la organización había mantenido posiciones que habilitaban la futura coexistencia en el territorio, en esta instancia se afianzó en una postura orientada a reivindicar la posesión en forma exclusiva.

En el nuevo esquema de intervención se priorizaron dos propósitos fundamentales: recrear un territorio continuo y garantizar las condiciones para que su dominio se exprese como posesión exclusiva en clave étnica, atendiendo a las implicancias de la noción de reparación histórica. Pero, ¿cómo recrear un territorio continuo y

\footnotetext{
12 Asociación Comunitaria Meguesoxochi del Teuco-Bermejito. Cómo solucionar de un modo práctico, rápido y económico la titulación de las 150.000 ha del Teuco-Bermejito a favor de la comunidad toba, salvando los intereses de los pobladores criollos, J.J. Castelli, agosto de 1995

${ }^{13}$ Corresponde a las parcelas parcelas 404 y 16 (ver Anexo, Figura 3)
} 
homogéneo sobre un escenario moldeado históricamente por relaciones sociales interétnicas? La respuesta fue la proyección sobre el espacio geográfico de un territorio multicultural basado en un modelo de tipo 'mosaico'. En el Interfluvio Teuco-Bermejito de fines del siglo $\mathrm{XX}$, esos propósitos no podían cumplirse en forma simultánea sin encarar un proceso drástico de re-territorialización.

\section{La identidad instrumentalizada}

La entrega del título, en 1999, configuró un nuevo escenario, con los indígenas 'empoderados' y habilitados legalmente para tomar decisiones de gestión del territorio. Con el reemplazo del modelo de los "agujeros de queso" por el modelo de mosaico se instaló una modalidad de abordaje de las relaciones interétnicas con una lógica excluyente basada en la afirmación incondicional de la diferencia, en sintonía con el multiculturalismo como paradigma de gestión de la diversidad. La conflictividad aumentó de la mano de la desconfianza, el recelo y los resentimientos previos que fueron reavivados en el marco de un escenario donde la etnicidad fue habilitada como un recurso movilizable.

Las intervenciones proyectadas introdujeron criterios de diferenciación que originaron nuevas tensiones en un complejo entramado preexistente de relaciones interétnicas. Las divergencias que se insinuaron desde entonces podrían resumirse del siguiente modo:

- entre criollos que deberían relocalizarse porque la nueva mensura los había 'arrojado' dentro de territorio indígena y criollos que podían permanecer en sus lugares;

- entre indígenas y criollos, porque, en el nuevo escenario, aparecían invertidos los términos de una relación de subordinación histórica, con los criollos en posesión precaria de la tierra y 'arrinconados' por los indígenas;

- entre ambos grupos y los órganos ejecutivos del Estado provincial;

- y, como veremos en seguida, también entre dirigentes de las organizaciones, agentes gubernamentales y referentes de las ONG que acompañaron el proceso de territorialización indígena.

Para afrontar esa situación y avanzar con el proceso de reasentamiento de población que permitiría a los indígenas tomar posesión de su territorio, el gobierno provincial impulsó la creación de una Comisión Mixta que fijaría los lineamientos y definiría los alcances, términos de referencia y objetivos del "Proyecto de Desarrollo Integrado Teuco-Bermejito" (PDITB). En ese marco, se promovieron espacios de acuerdo con la propuesta de implementar normas de convivencia entre indígenas y criollos, que funcionarían como un reglamento interno transitorio. Ambos sectores suscribieron actas para establecer acuerdos en esa dirección, pero, por parte de la Asociación Meguesoxochi, algunos puntos generaban especial controversia. En particular, la decisión acerca de si los criollos ancianos y las familias mixtas podían permanecer en 
sus lugares o si deberían relocalizarse. La resolución de ese punto se postergó más allá de los primeros acuerdos, pues refería a la posibilidad de establecer casos de excepción entre la población a relocalizar. A medida que avanzaban las consultas, la Asociación asumió posturas cada vez más intransigentes, incluso su comisión directiva definió en asamblea que todos los criollos debían abandonar el territorio indígena. Los fundamentos esgrimidos hacían pesar la memoria de una historia de sometimientos, de relaciones de subordinación y trato desigual por parte de los criollos. El nuevo escenario invertía esos términos y ponía a los indígenas en la situación de poder decidir por la suerte de sus históricos rivales en el territorio. El endurecimiento de esa posición encontraba argumentos en consideraciones de orden práctico sobre las dificultades que traería aparejadas la permanencia de criollos en el territorio. Cada situación particular generaba suspicacias en torno al hecho de que cualquier excepción al criterio de exclusión representaba la posibilidad de erosionar la territorialidad indígena.

En base a una aprensión similar, se arguyó también que los matrimonios mixtos con mujer indígena habilitaban a que el varón criollo pudiera adquirir derechos sobre las tierras ocupadas. Aquel argumento, si bien podía presentarse como un enunciado general, fue esgrimido oportunamente para dirimir disputas internas que ya no tenían que ver con la afirmación de reivindicaciones identitarias. Por otra parte, esa misma disociación instrumental entre los fundamentos de la reivindicación indígena y las prácticas promovidas desde la MEGUE se había revelado de manera elocuente tiempo atrás, luego de la entrega del título comunitario, cuando tomaron estado público los acuerdos suscriptos por el presidente de la asociación y empresarios madereros de la región. Si hasta 1999 la organización había fomentado un discurso crítico de la depredación forestal y había promovido proyectos para avanzar hacia modelos de gestión sustentable, a partir de la obtención del título había quedado facultada incondicionalmente para tomar decisiones en torno a la gestión de los recursos naturales de su territorio.

Desde 1999 las estrategias asumidas por la organización condujeron a un proceso de territorialización que se configuró como una estrategia de cierre por exclusión (Parkin, 1984). La demanda de reconocimiento desde la afirmación identitaria se constituyó como un fin, pero también como un medio para disputar la redistribución de recursos. Una vez que fue reconocido y sancionado jurídicamente el derecho sobre el territorio, la Asociación se ubicó en una posición dominante sobre los grupos criollos y desde allí promovió acciones orientadas a garantizar la posesión efectiva sobre su propiedad. En ese esquema, el criollo aparece en una posición subordinada, pero representa una amenaza.

En los enfoques actuales en torno al fenómeno étnico, se pueden identificar esquemáticamente dos líneas contrapuestas que perfilan posiciones reduccionistas: el primordialismo, que considera a la etnicidad como algo dado que constriñe la autonomía de los sujetos a través de lazos de solidaridad primarios; y el 
constructivismo radical expresado como instrumentalismo, que tiende a concebirla como un recurso que se moviliza estratégicamente (Hutchinson y Smith, 1996; Río Ruiz, 2002). Si bien aquí partimos de que las identidades emergentes son el resultado de procesos de subjetivación que suponen una recreación permanente -contra cualquier resabio esencialista-, también es necesario considerar que las identidades no se generan a partir de la nada y que se configuran en torno de un repertorio limitado. En ese sentido, el tomar distancia del esencialismo no significa asumir que estamos ante un sujeto cínico que define instrumentalmente su identidad, sino que las estrategias de definición política de las identidades deben estar orientadas por un marco de referencia que aporte condiciones de posibilidad objetivas. ${ }^{14}$

En el temprano análisis weberiano, la etnicidad se encuadra en la definición de acción comunitaria política y remite a las estrategias de cierre social que caracterizan a toda forma de estratificación, donde el grupo étnico remite al hecho objetivado por la creencia de que un grupo de individuos forma parte de un colectivo con una procedencia común y que reúne rasgos culturales, orígenes y una historia distintiva (Weber, 1944). La politización de las diferencias culturales es eficaz si puede asentarse sobre una creencia de los miembros del colectivo que la vuelva significativa. Asimismo, las diferencias culturales por sí mismas no generan acción política, sino que es esta la que promueve la conformación de una comunidad étnica al apoyarse sobre la base de una herencia cultural como criterio de pertenencia. Aunque admitamos que los diacríticos culturales pueden ser manipulados, es necesaria alguna forma de objetivación previa que permita dotarlos de sentido como parte de repertorios configurados históricamente. Los símbolos que componen los repertorios culturales imponen una relativa resistencia a las manipulaciones arbitrarias, tienen una "plasticidad limitada" (Río Ruiz, 2002: 98).

La estrategia de territorialización étnica que promueve la organización qom se recorta sobre un escenario caracterizado por una reestructuración del campo jurídico, en el que, a partir de la puesta en valor de la diversidad cultural, la etnicidad tiende a presentarse como un recurso movilizable o como valor estratégico. El marco jurídico del neoindigenismo establece criterios para definir al sujeto portador de derechos. La

${ }^{14}$ A partir de Barth (1976) se asumió que la identidad étnica es relacional y que lo cultural remite a prácticas de diferenciación más que a un patrimonio o un acervo idealizado. Si los enfoques primordialistas presentan un sujeto preconstituido, en el marco de las perspectivas constructivistas, el sujeto étnico tiende a ser contingente y transitorio. Sin embargo, el énfasis puesto en el rechazo del primordialismo condujo también a otra forma de reduccionismo: la idea de que los marcadores culturales pueden ser manipulados según determinados fines conduce a los enfoques instrumentalistas de la etnicidad. En esos casos, la etnicidad tiende a ser concebida como recurso o capital simbólico, manipulada a través de la movilización de diacríticos culturales. Los grupos étnicos son definidos como grupos de interés cuyos mecanismos de adscripción operan en base a estructuras de incentivos, y la solidaridad étnica es un subproducto de ventajas discriminadas racionalmente. La adscripción étnica es presentada como una decisión voluntaria animada por un cálculo instrumental, mientras que para los grupos subalternos constituye una estrategia eficaz que les permite acceder a recursos en distintos ámbitos del espacio social (Glazer y Moynihan, 1975) 
cultura pasa a ser considerada como una credencial de presentación y los propios sujetos indígenas en muchos casos estructuran sus demandas a través de un uso estratégico de la identidad como forma de contrarrestar desigualdades y acceder a recursos que posibiliten su reproducción social.

En lugar de promover relaciones más igualitarias y horizontales, la lógica del mosaico multicultural reforzó las fronteras étnicas y los estereotipos. Para los indígenas, la revalorización de la cultura no solo responde a un propósito de autoafirmación identitaria, sino que también se convierte en un recurso que se moviliza en demanda del cumplimiento de derechos reconocidos formalmente.

Es importante diferenciar a la etnicidad como fenómeno o criterio de estratificación respecto de usos instrumentales, como es el caso de los enfoques que tematizan las demandas indígenas en términos de esencialismo estratégico, o de manipulación de diacríticos culturales movilizados como recurso. Precisamente, los enfoques instrumentalistas de la etnicidad se apoyan sobre la indiferenciación de ambos planos y el sujeto queda diluido en un conjunto de prácticas sin referencias objetivas. Para nosotros, se trata de las condiciones de posibilidad, objetivadas como escenarios históricos específicos, que habilitan o bloquean el despliegue de las estrategias a través de las cuales los sujetos se constituyen y recrean. En este punto, recuperamos el encuadre metodológico del contextualismo radical que propone Stuart Hall para evitar caer en las lecturas reduccionistas del vínculo entre acción y estructura; esto es, pensar en las condiciones de posibilidad de ciertas articulaciones como una no necesaria correspondencia "entre las condiciones de una relación o práctica social y las diferentes maneras en las que puede ser representada" (Hall, 2010: 208).

\section{A modo de cierre}

En escenarios caracterizados por los nuevos ordenamientos jurídicos multiculturales, los enfoques instrumentalistas de la etnicidad prosperan porque tienen a su favor la apariencia de verdad que genera la correspondencia objetiva con las prácticas que configuran las estrategias de los agentes. En ese sentido, al analizar la experiencia de la MEGUE podemos acordar, en primera instancia, con aquellas interpretaciones que sostienen que lo indígena es una apuesta o una elección, una identidad actuada en función de las especulaciones de un sujeto cínico. Los integrantes de la MEGUE hoy son propietarios de un territorio reivindicado mediante una estrategia referenciada centralmente en la etnicidad. Eso les permitió presentarse como un sujeto empoderado con un capital simbólico que incrementó su valor en el contexto de la juridización de la cuestión indígena. Sin embargo, la razonabilidad de las prácticas, el hecho de que podamos identificar una conexión de sentido o una lógica subyacente a la estrategia promovida, no implica remitir esa lógica a una racionalidad intrínseca del sujeto. Es decir, los usos instrumentales de la identidad no presuponen un sujeto portador de una racionalidad instrumental. 
Para insistir con esto último no está de más resaltar la ruptura necesaria entre la perspectiva de los actores y la mirada del analista que interpreta. Precisamente, podemos afirmar que la percepción en torno a las prácticas que condicionan las interacciones cotidianas de los agentes involucrados en las disputas territoriales del Interfluvio está permeada por consideraciones de orden instrumental. Sus prácticas se orientan como si la identidad fuese una herramienta necesaria. Pero esto no se deriva de un obstáculo epistemológico encarnado en la racionalidad del agente individual, sino que el escenario en el que se desarrolla la disputa por el acceso a la tierra está configurado como un mercado de bienes simbólicos que condiciona estructuralmente las percepciones. Lo que vemos en el Interfluvio es un juego constante de interacciones orientadas como cálculos estratégicos, como un ajedrez que inspira un modelo basado en la teoría de los juegos. A partir de que la etnicidad es un recurso en un espacio social cuya lógica funciona como una estructura de incentivos, los agentes orientan sus estrategias instrumentalmente.

La territorialidad étnica que promueve la Asociación Meguesoxochi es una estrategia de territorialización centrada fundamentalmente en el plano jurídico. Fue el resultado eficaz de una estrategia reivindicativa orientada a lograr el reconocimiento del derecho sobre el territorio. Esto le imprimió un rasgo singular que se sostuvo en el tiempo: la preeminencia de lo simbólico sobre lo material. En base a esa jerarquía, se ordenan sus dimensiones constitutivas: en primer lugar, el plano reivindicativo; sobre esa base la demarcación de límites; y por último la apropiación material a través de la posesión efectiva. La disputa por la tierra se desarrolla en un escenario donde el capital simbólico que representan las credenciales 'étnicas' tiene un peso específico sobresaliente y determina su estrategia territorial. La territorialidad es a la vez una demarcación de fronteras étnicas.

\section{Referencias}

Bazalote, Alejandro (2002). Reasentamiento forzoso de población y regularización territorial en el Interfluvio Teuco-Bermejito (Provincia de Chaco). Cuadernos de Antropología Social. No 16, pp. 165-184.

Bazalote, Alejandro y Radovich, Juan (2003). Multiculturalidad y economía: El caso del interfluvio Teuco-Bermejito. RUNA. No 24, pp. 103-122.

Barrios, Gabriela (2005). Armándose de la identidad necesaria. 'Tradiciones' de la población criolla ante la relocalización compulsiva derivada de la devolución de tierras a la comunidad toba-Interfluvio Teuco-Bermejito, Chaco. Rozé y Pratesi (Comps.) Conflictos centrales en la periferia de la globalización. LibrosenRed, pp. 243-266.

Barth, Fredrik (1976). Los grupos étnicos y sus fronteras. La organización social de las diferencias culturales, México D.F.: Fondo de Cultura Económica, [1969] 
Beck, Hugo Humberto (1994). Las relaciones entre blancos e indios en los territorios nacionales de Chaco y Formosa. 1885-1950, Cuadernos de Geohistoria Regional $N^{\circ} 29$, Resistencia: Instituto de Investigaciones Geohistóricas-CONICET.

Bello, Álvaro (2004). Etnicidad y ciudadanía en América Latina. La acción colectiva de los pueblos indígenas. Santiago de Chile: CEPAL

Centro de Estudios Legales y Sociales (1991). El Grito Toba de Colonia Teuco. El reclamo aborigen de tierras más importante del siglo. Cuadernos del CELS, Año II, No5

Glazer, N. y Moynihan, D. (1975). Ethnicity: Theory and Experience. Cambridge, Mass.: Harvard University Press

Haesbaert, Rogerio (2004). O mito da Desterritorialização. Do "fim dos territórios" à multiterritorialidade. Río de Janeiro: Ed. Bertrand.

Hall, Stuart (2010). "Significación, representación, ideología: Alhusser y los debates postestructuralistas". En Sin garantías. Trayectorias y problemáticas en estudios culturales, Popayán-Lima-Quito: Envión Editores-IEP- Instituto PensarUniversidad Andina Simón Bolívar. [1985] pp. 193-220.

Hammersley, M. y Atkinson, P. (1994). Etnografía. Métodos de investigación, Barcelona: Paidós.

Hutchinson, J. y Smith, A. (1996). Ethnicity. Oxford: Oxford University Press.

Jacob, Ricardo (1994). Las relaciones entre indios, norteños y gringos, en torno a la posesión de la tierra en el noroeste chaqueño. XIV Encuentro de Geohistoria Regional, Resistencia: Instituto de Investigaciones Geohistóricas-CONICET, pp. 191-207.

Martínez Sarasola, Carlos (1992). Nuestros paisanos los indios. Buenos Aires: Ed. Emecé.

Mases, Enrique (2000). Estado y cuestión indígena: Argentina 1878-1885. En Suriano, Juan (Comp.) La cuestión social en Argentina 1870-1943, Buenos Aires: La Colmena.

Parkin, Frank (1984). Marxismo y teoría de clases. Una crítica burguesa. Madrid: EspasaCalpe.

PDITB - Programa de Sustentabilidad Ambiental (2001). Informe Final. Secretaría de Planificación y Evaluación de Resultados/Consejo Federal de Inversiones

Programa de Sustentabilidad Ambiental

Raffestin, Claude (1993). Por uma geografia do poder. San Pablo: Ática.

Río Ruiz, Manuel Ángel (2002). Visiones de la etnicidad. Reis. Revista española de investigaciones sociológicas, № 98, pp. 79-106

Sack, Robert (1986). Human Territoriality: its theory and history. Cambridge: Cambridge University Press.

Santos, Milton (2000). La naturaleza del espacio. Técnica y Tiempo. Razón y emoción. Barcelona: Ariel.

Weber, Max (1944). Economía y Sociedad. México: Fondo de Cultura Económica.

\section{Diarios y Revistas}


NORTE, Resistencia, 15/IV/1990 y 06/III/1993

CHACO Y FORMOSA, Revista de la Asociación de Fomento de los Territorios de Chaco y Formosa, Resistencia, Año XVIII, N¹88, setiembre de 1944

\section{Anexo}

\section{Figura 1}

Ubicación del Interfluvio Teuco-Bermejito en la Provincia de Chaco, República Argentina 


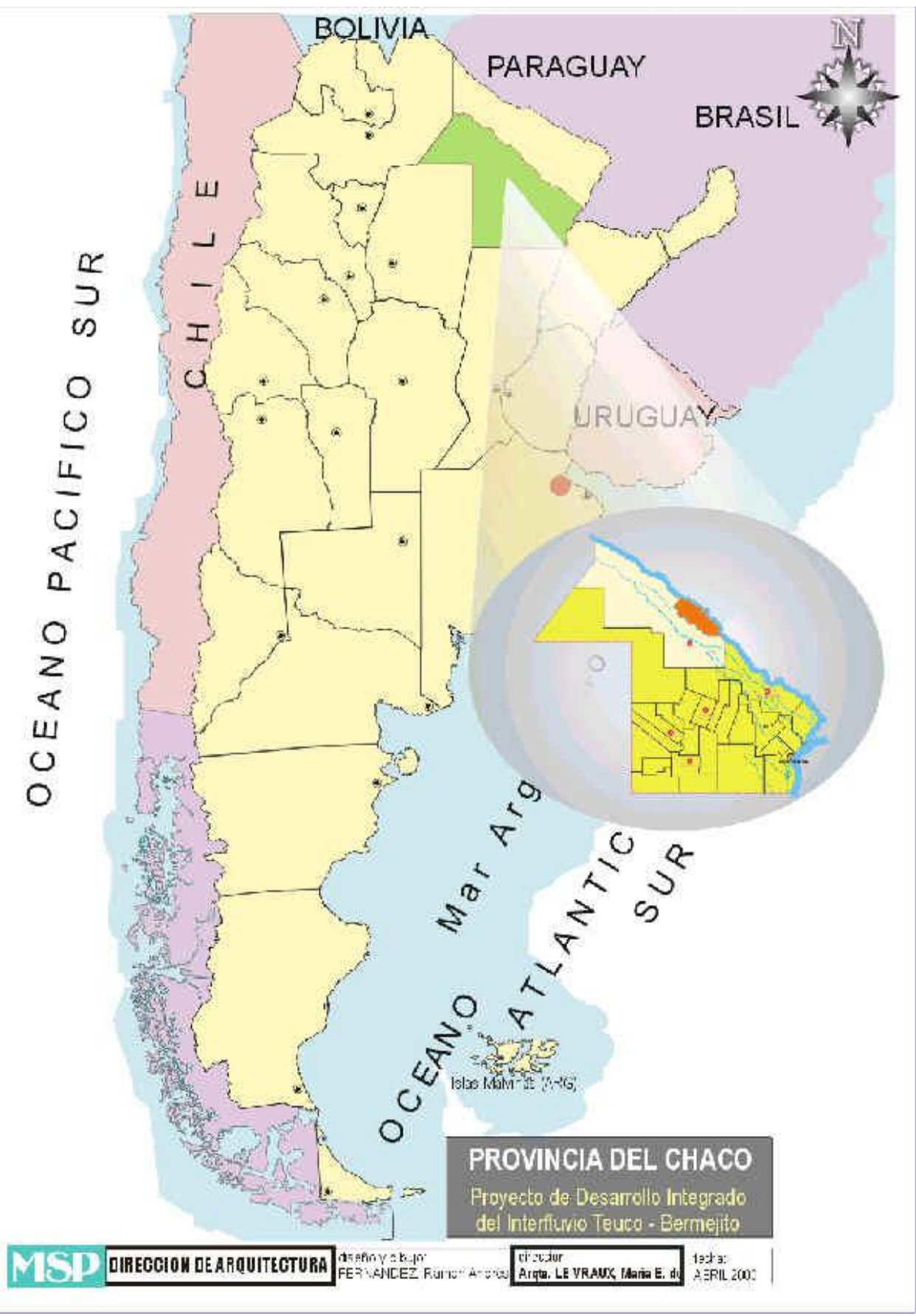

Fuente: Proyecto de Desarrollo Integrado Teuco Bermejito

\section{Anexo}

\section{Figura 2}

Croquis. Propuesta alternativa mensura presentada por la Asociación Meguesoxochi al Gobierno del Chaco (1995) 


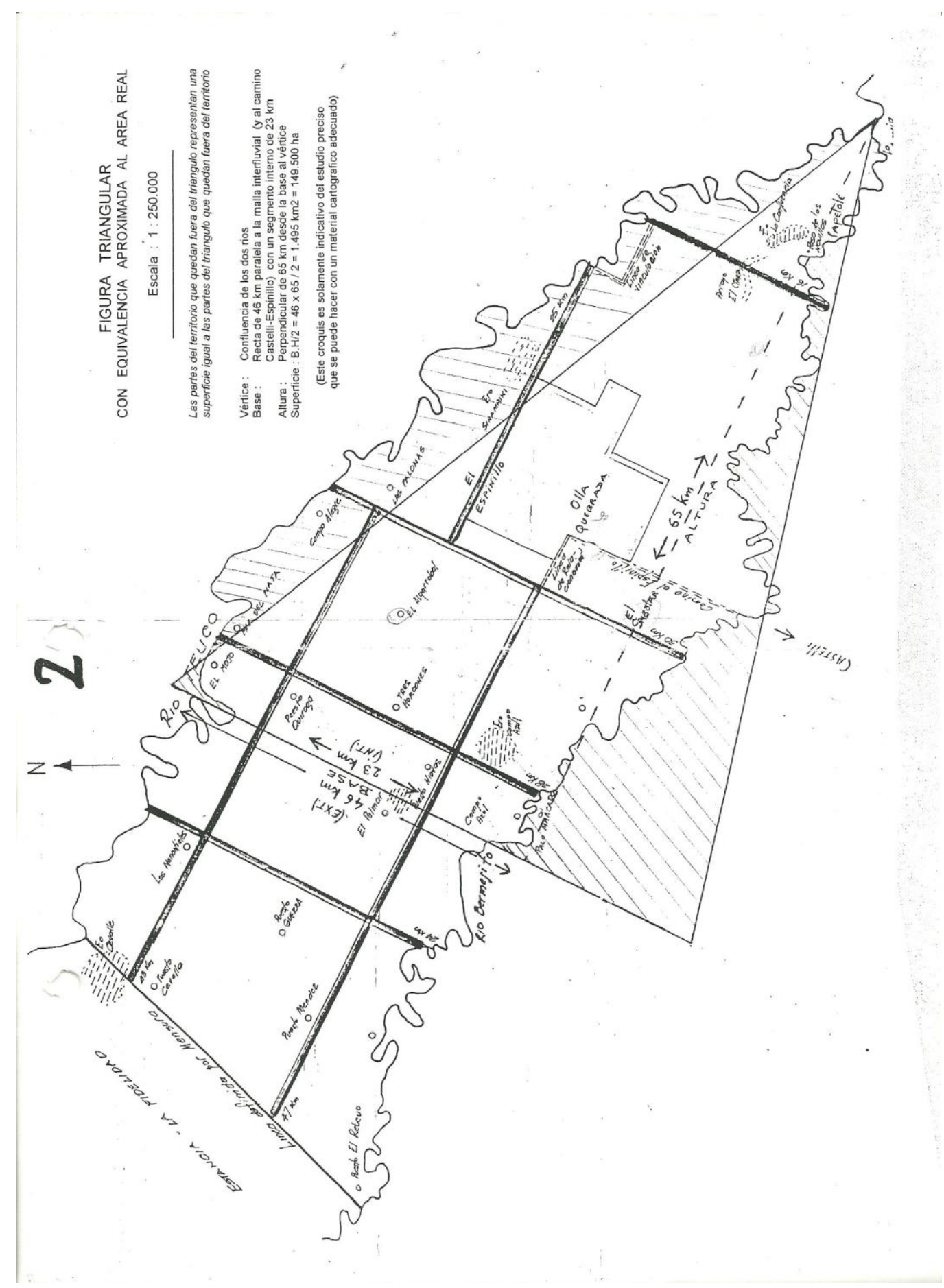

Fuente: Asociación Comunitaria Meguesoxochi del Teuco-Bermejito. Cómo solucionar de un modo práctico, rápido y económico la titulación de las 150.000 ha del TeucoBermejito a favor de la comunidad toba, salvando los intereses de los pobladores criollos. J.J. Castelli, agosto de 1995. 


\section{Anexo}

Figura 3

Área afectada al Proyecto de Desarrollo integrado Teuco-Bermejito

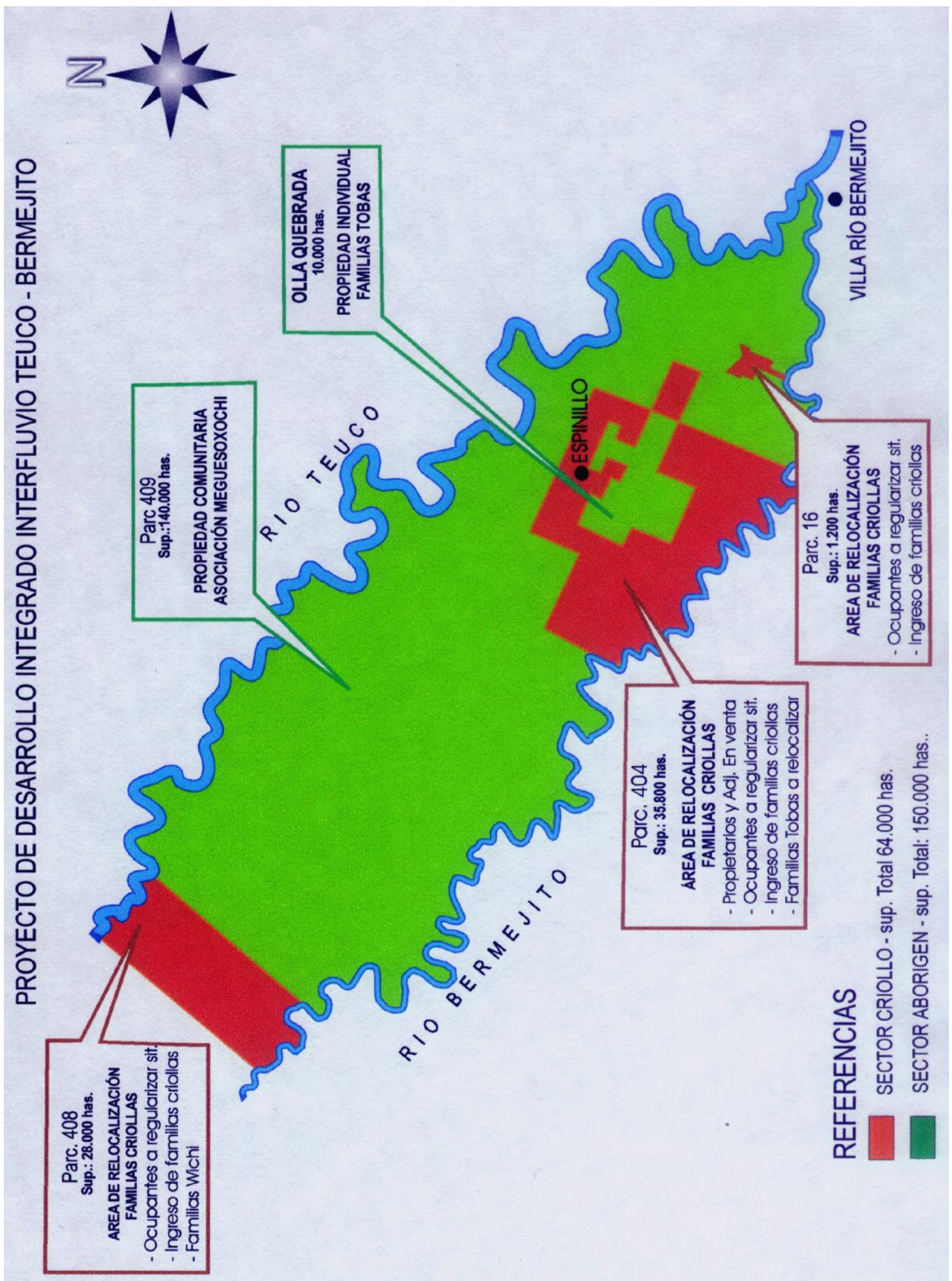


De Prácticas y discursos/ Universidad Nacional del Nordeste/ Centro de Estudios Sociales

Año 4, Número 5, Julio-Diciembre, 2015

ISSN 2250-6942

Fuente: Proyecto de Desarrollo Integrado Teuco Bermejito 